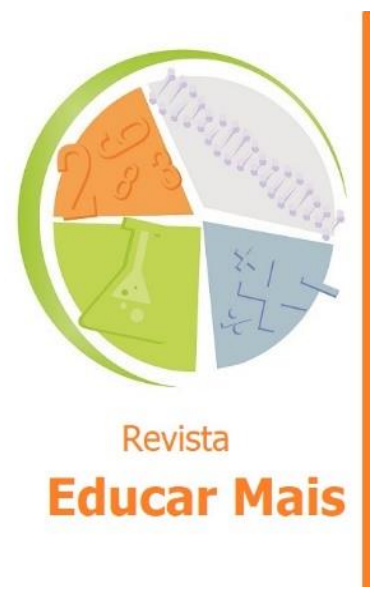

\title{
A incidência de bullying na escola pública e o papel da gestão no enfrentamento da violência
}

\author{
The incidence of bullying at public school and the role of management \\ in coping with violence
}

\section{La incidencia del acoso en la escuela pública y el papel de la gestión para enfrentar la violencia}

Silvia Diana de Lima Silva Orique ${ }^{1}$; Lúcio Jorge Hammes²; Emanuel Moita ${ }^{3}$

\section{RESUMO}

Este trabalho tem o objetivo analisar a incidência de bullying em Escolas Públicas, verificando as ações da gestão em relação a esta violência, que presente no ambiente escolar e tem trazido graves consequências para quem a sofre. A pesquisa foi desenvolvida em duas escolas, sendo uma municipal e outra estadual, situadas no município de Jaguarão, Rio Grande do Sul. Nestas escolas foram desenvolvidas entrevistas com professores, equipes de gestão e pais, permitindo conhecer melhor a realidade das escolas, especialmente, as ocorrências de bullying. Os dados indicam que uma das escolas ainda não tem uma proposta efetiva voltada ao enfrentamento do bullying, ao passo que a outra já tem um trabalho em busca da cultura de paz, permitindo amenizar os efeitos das agressões. No ambiente escolar, buscar alternativas para reduzir o bullying é uma ação básica da educação.

Palavras-chave: Bullying; Escola; Gestão; Violência.

\begin{abstract}
This work aims to report the incidence of bullying in Public Schools in the municipality of Jaguarão, State of Rio Grande do Sul, verifying management actions in relation to this violence, which is increasingly present in the school environment and has brought serious consequences for those who suffer it. The research is done in two schools, one being municipal and other state. From interviews with teachers, management staff and parents, it was possible to get to know the reality of schools better, as well as the occurrences of bullying. The data indicate that the municipal school does not yet have an effective proposal aimed at coping with bullying, while the state school has already worked on the culture of peace to soften the effects of aggressions. In the school environment, look for alternatives to reduce bullying is a basic education action.
\end{abstract}

Keywords: Bullying; School; Management; violence.

\section{RESUMEN}

Este trabajo tiene como objetivo reportar la incidencia del acoso escolar en las escuelas públicas en el municipio de Jaguarão, Estado de Rio Grande do Sul, verificando acciones de gestión en relación con esta violencia, cada vez más presente en el ámbito escolar y ha traído consigo graves consecuencias para quem a sofre. A pesquisa é feita em duas escolas, sendo uma municipal y otro estado. De entrevistas con maestros, personal

${ }^{1}$ Graduação em História e Mestrando do Programa de Pós-Graduação em Educação (PPGEdu) da Universidade Federal do Pampa (UNIPAMPA), Jaguarão/RS - Brasil. E-mail: silviaorique@yahoo.com.br

${ }^{2}$ Doutor em Educação e Professor Programa de Pós-Graduação em Educação (PPGEdu) da Universidade Federal do Pampa (UNIPAMPA), Jaguarão/RS - Brasil. E-mail: luciojh@gmail.com.

${ }^{3}$ Mestrando em Políticas Públicas na Universidade Estadual do Ceará (UECE), Fortaleza/CE - Brasil. E-mail: emanuel_lucasfm@hotmail.com 
administrativo y padres, Se pudo conocer mejor la realidad de las escuelas, así como las ocurrencias del bullying. Los datos indican que la escuela municipal aún no cuenta con una propuesta efectiva dirigida a hacer frente al acoso escolar, mientras que la escuela pública ya ha trabajado en la cultura de paz para ablandar los efectos de las agresiones. En el entorno escolar, busque alternativas para reducir el acoso es una acción de educación básica.

Palabras clave: Acoso, Colegio. Gestión. violencia.

\section{INTRODUÇÃO}

Este artigo busca analisar a incidência de bullying ${ }^{4}$ em duas escolas públicas no município de Jaguarão, Estado do Rio Grande do Sul. Estuda as ações da gestão em relação a esta violência praticada no ambiente escolar, com consequências para quem a sofre, para quem a pratica e quem assiste. Parte desta pesquisa foi apresentada no I Simpósio Nacional de Estratégias e Multidebates da Educação e publicado um resumo ampliado nos Anais deste Evento, organizado por Instituições de Ensino Superior que se associaram para promover debates acadêmico-científicos entre Programas de Mestrado e Doutorado em Educação - Profissionais e Acadêmicos localizados em outros estados brasileiros (ORIQUE; HAMMES, 2020).

Bullying, de acordo com Pereira (2009) se manifesta por meio de insultos, apelidos cruéis, acusações injustas, intimidações, subtração de pertences, além da atuação de grupos que ridicularizam, hostilizam e excluem outros alunos. Para Silva (2010) o bullying é um problema endêmico presente nas escolas de todo o mundo, tendo a ver com agressões, ações desrespeitosas e assédios, executados de forma repetitiva e intencional por parte dos agressores. Salienta ainda que as atitudes violentas não apresentam motivações específicas ou justificáveis.

De acordo com a definição de Houaiss (2015) bullying é o comportamento insistente de quem procura intimidar, por meio de violência física ou psicológica, alguém incapaz de se defender, está geralmente presente em escolas. Não há uma tradução exata na língua portuguesa para a palavra bullying, ao consultar o dicionário de inglês (The Landmark Dicionary, 2014) é possível traduzir a palavra, a qual tem a grafia "bully", por tirano, brigão, valentão, alguém que maltrata, ameaça e intimida. Portanto, o bullying é algo que precisa ser melhor conhecido e estudado, necessitando de atenção por parte da família, escola e sociedade como um todo.

O psicólogo norueguês Dan Olwens, considerado o pioneiro na pesquisa sobre o bullying, fez vários estudos sobre a temática na Universidade de Bergen-Noruega entre 1970 e 1990, analisando variáveis entre frequências e tipos de agressão, locais de maior risco e percepção dos agressores. De acordo com Fante (2018) os estudos de Olwens constataram que a cada sete alunos, um estava envolvido em casos de bullying, com isso houve uma Campanha Nacional anti-bullying com o apoio do governo nas escolas norueguesas, reduzindo em $50 \%$ a violência. A partir de então outros países se sentiram motivados a promoverem campanhas contra o bullying.

\footnotetext{
${ }^{4}$ Como oficialmente não há um termo na língua portuguesa que poderia expressar o correspondente inglês Bullying -, conceito que toma emprestado noções de diferentes campos de conhecimento e tem suas raízes nas lutas contra todo tipo de violência (incluindo a violência física, cultural e o assédio moral) presentes em instituições como as escolas onde se encontram adolescentes e jovens. - e, por causa da diversidade de sentidos do termo violência, preferimos usar neste artigo o termo bullying (original e em grifo) incluindo toda riqueza desta categoria.
} 
Bullying pode marcar profundamente as pessoas que o sofrem, tendo consequências irreversíveis. Pela falta de conhecimento da situação, torna-se difícil identificá-lo, acabando por ser confundido com um desentendimento entre alunos, professores e funcionários. Por isso, o estudo sobre o tema se impõe, podendo inclusive aproveitar campanhas voltadas ao enfrentamento da violência que atinge os jovens em idade escolar.

A pesquisa aqui analisada neste artigo tem enfoque no bullying entre alunos de duas escolas públicas de Jaguarão, Rio Grande do Sul, Brasil. O trabalho se divide em 3 tópicos, identificando o potencial de bullying e suas consequências, além dos sujeitos envolvidos com esta forma de violência. Estuda acontecimentos que causaram comoção e tiveram o bullying como motivação, traz para o debate a legislação referente à violência e expõe propostas de autores sobre o tema.

O lócus da pesquisa em análise são duas escolas públicas de Jaguarão, sendo uma municipal e outra estadual. Os dados foram coletados através de entrevistas com a direção, orientação educacional, professores e pais, possibilitando traçar um diagnóstico das ações desenvolvidas pela gestão, constatando também a incidência de bullying. A Escola Municipal será identificada nesta análise como "Escola M" e a Escola Estadual como "Escola E", permitindo certo anonimato para que as instituições e os sujeitos sejam mais difíceis à identificação.

A pesquisa é de cunho qualitativo e tem como objetivo analisar as situações de bullying nas escolas e verificar as providências tomadas pela gestão para minimizar os efeitos desta forma de violência. Como instrumento da coleta de dados da "Escola M" foi utilizado o Diário de Campo e uma entrevista semiestruturada com a direção, buscando compreender a realidade vivenciada por alunos de uma turma de sexto ano do Ensino Fundamental e as ações efetuadas pela instituição.

A coleta de dados da "Escola E" foi realizada através de uma entrevista com três mães cujos filhos cursavam os anos iniciais e finais do ensino fundamental. Para o estudo diagnóstico desta escola foi realizada entrevista semiestruturada com a orientadora educacional e posteriormente, um questionário semiestruturado com um professor dos anos finais do ensino fundamental, etapa em que se constata que casos de bullying normalmente são mais graves. As entrevistas tinham o intuito de averiguar situações de bullying na escola e a visão do professore sobre a violência.

Uma primeira análise dos dados indica que a "Escola $M$ " revela ações mais paliativas, sem planejamento estruturado de prevenção ou redução da violência, enquanto a "Escola E" já possui um projeto para o enfrentamento da violência que, em seu entendimento tem sido eficaz. O estudo revela a persistência do bullying nas duas escolas pesquisadas, indicando caminhos de gestão para o enfrentamento deste, destacando a prevenção como forma de combate às agressões sistemáticas e o importante papel das instituições para o desenvolvimento de ações para a diminuição do bullying. Além da conscientização sobre o problema, sugere-se a interação com as famílias.

Para os sujeitos que participaram da pesquisa foram utilizados pseudônimos, a fim de resguardar a identidade destes. As três mães entrevistadas serão denominadas pela letra $M$ referindo-se a palavra "Mãe" seguida pela numeração crescente de acordo com a ordem a ser exposta no texto e após a profissão de cada uma. O restante dos sujeitos será identificado pelas suas funções. 


\title{
2. BULLYING NÃO É BRINCADEIRA
}

Bullying ocorre em mais variados lugares onde há pessoas que não compreendem as consequências das suas atitudes, na rua, na escola, no trabalho, ou na própria família. Neste artigo analisamos a incidência de Bullying na escola, local onde se desencadeia com frequência e causa mais problemas às vítimas. Na maioria dos casos, quando percebido, já está instaurado na instituição, pois ainda há dificuldade em diferenciá-lo de um conflito passageiro entre pares.

Segundo Fante (2018) o bullying é um conceito específico e bem definido, apresentando características próprias, sendo a mais grave os traumas psíquicos causados às vítimas.

\begin{abstract}
Bullying é um conjunto de atitudes agressivas, intencionais e repetitivas que ocorrem sem motivação evidente, adotado por um ou mais alunos contra outro(s) causando dor, angústia e sofrimento. Insultos, intimidações, apelidos cruéis, gozações que magoam profundamente, acusações injustas, atuação de grupos que hostilizam, ridicularizam e infernizam a vida de outros alunos levando-os à exclusão, além de danos físicos, morais e materiais, são algumas das manifestações do comportamento bullying (FANTE, 2018, p.28; 29).
\end{abstract}

O bullying não é algo novo, mas faz somente algumas décadas que tem sido estudado como tal. Até pouco tempo era visto como "brincadeiras inocentes", próprias da idade. Longe disso, o bullying pode causar em suas vítimas sérios transtornos. De acordo com Albino \& Terêncio (2012) quem sofre bullying passa a ter como consequências: baixa autoestima, baixo rendimento e evasão escolar, agressividade, ansiedade, estresse. Podendo, ainda, progredir para transtornos psicopatológicos graves, fobias e depressões, além de ideias suicidas ou desejos intensos de vingança.

Nesse sentido, a presença ou não de um bom suporte familiar pode ser decisiva para que o infante supere as situações traumáticas vivenciadas ou, ao contrário, entreguese ao isolamento social como uma forma de fuga e proteção contra agressões. (ALBINO; TERÊNCIO, 2012, p. 03).

Fante (2018) relata que os estudos feitos por Dan Olwens na Universidade de Bergen-Noruega, entre as décadas de 1970 e 1990, ocorreram em um período em que a violência escolar aumentava e preocupava muito pais e professores. Neste mesmo período, ocorreu o suicídio de três estudantes entre 10 e 14 anos que provavelmente tiveram como motivações os maus-tratos sofridos por seus colegas de escola. A partir disso, o governo da Noruega, lançou uma campanha de combate ao bullying.

Ainda segundo Fante (2018) Olwens desenvolveu critérios para diferenciar o bullying de outras violências, pesquisando oitenta e quatro alunos, trezentos a quatrocentos professores e mil pais. 0 programa de intervenção criado por Olwens pretendia desenvolver regras claras contra o bullying, além de alcançar um envolvimento ativo por parte de professores e pais, aumentando a conscientização sobre o problema, a fim de eliminar os mitos sobre bullying, promovendo ainda apoio e proteção para as vítimas.

Um estudo realizado pela Associação Brasileira Multiprofissional de Proteção à Infância e à Adolescência (ABRAPIA) em parceria com a PETROBRAS em escolas do Rio de Janeiro citou os estudos noruegueses propostos por Olwens, o qual utilizou um questionário constituído de um total de vinte e cinco questões com respostas de múltipla escolha para verificar a frequência, tipos de agressões, locais de maior risco, tipos de agressores e percepções individuais quanto ao número de 
agressores. A partir deste instrumento era possível apurar as situações de vitimização/agressão pelo ponto de vista da própria criança.

Bullying tem sido relacionado ou motivado por atos de violência. O Massacre de Columbine (MARRAN, 2018) nos Estados Unidos em 1999, resultou em mortos e feridos, além do suicídio dos atiradores. Dois jovens entraram armados na escola em que haviam estudado, com armas de fogo e bombas caseiras, além de facas. $O$ ataque resultou na morte de doze alunos e um professor e vinte e uma pessoas feridas, a maioria na biblioteca. De acordo com o testemunho de sobreviventes, ambos sofriam bullying, porém, as investigações revelam que as provocações de colegas não teriam motivado o tiroteio. Mesmo assim, o Massacre de Columbine influenciou e pode ter sido exemplo para chacinas em outras escolas, inclusive no Brasil, as quais teriam como motivação o bullying.

O ataque ao Instituto Politécnico da Virgínia (ANDRADE, 2017) em 16 de abril de 2007, teve trinta e três mortos, incluindo o atirador e vinte e uma pessoas feridas. No dia 18 de abril, a rede de TV americana NBC, recebeu uma encomenda enviada pelo atirador contendo um texto, fotos e vídeos em que relata os maus tratos sofridos e todo o ódio que sentia. O material começou a ser produzido seis dias antes do massacre.

No Brasil, tragédias em escolas de diferentes lugares também têm como pano de fundo o bullying com destaque para o massacre de Realengo (CASTRO, 2020) que deixou doze mortos na Escola Municipal Tasso da Silveira, no Rio de Janeiro, em 2011. O atirador, ex-aluno da escola, que se suicidou logo após ser atingido por um policial, deixou em uma carta em que sugeria ter sofrido bullyiyng.

No ano de 2017 um aluno disparou contra colegas, matando dois e deixando quatro feridos, na Escola Particular Goyazes (LOURENÇO, 2020) em Goiânia. O estudante disse sofrer bullying e que teria planejado por dois meses a ação, baseando-se nos ataques de Columbine, nos Estados Unidos em 1999 e em Realengo, no Rio de Janeiro em 2011. Para o delegado relatou que a intenção seria matar apenas o colega que praticava o bullying, porém, após atingir este, sentiu a necessidade de matar outros.

Em 2019, na Escola Estadual Professor Raul Brasil, em São Paulo, dois atiradores deixaram dez mortos. Enquanto um deles disparava o outro desferia golpes com uma machadinha e lançava dardos com uma besta, o ataque durou cerca de vinte minutos. Antes de entrarem na escola o tio de um dos atiradores também foi morto, após a chacina, um dos atiradores matou seu comparsa e se suicidou. O ataque ficou conhecido como o Massacre de Suzano (SUDRÉ, 2020) tendo como uma das causas do massacre, a violência que o autor sofreu (bullying) e que desencadeou mais violência com o uso de arma de fogo.

Homicídios seguidos de suicídios poderiam ser considerados como situações de extrema violência ou a situação que leva ao suicídio as vítimas que não suportam mais as agressões. Bullying leva a consequências para os envolvidos. Por isso, sugere-se trabalhar a empatia, o respeito, a tolerância.

É importante que educadores, gestores, pais e alunos tomem consciência de que é direito de crianças e adolescentes estudarem num ambiente saudável e isto inclui que todos sejam aceitos e respeitados em suas diferenças e, conscientes, trabalhem para que estes direitos sejam garantidos (CARREIRA, 2005, P. 32).

Uma modalidade de bullying, que vem se intensificando é o cyberbullying, conhecido como bullying virtual que ocorre através da tecnologia, atingindo também as escolas, mas ultrapassa os muros 
desta, permitindo inclusive o anonimato dos agressores, criando certa blindagem dando a impressão de que pode agir sem ser descoberto.

O praticante do ciberbullying utiliza os recursos para constranger, humilhar, expor. Pode utilizar perfis falsos e disseminar intrigas, fazer comentários preconceituosos, expor suas vítimas. As mensagens depreciativas podem ser acompanhadas de fotografias alteradas ou não. As consequências são desastrosas e podem afetar também famílias e amigos das vítimas.

\subsection{Algumas consequências ligadas ao bullying}

Para Silva (2010) é preciso refletir que o bullying pode levar a quadros clínicos que exigirão tratamento para que sejam superados. A autora afirma "A prática de bullying agrava o problema preexistente, assim como pode abrir quadros graves de transtorno psíquicos e/ou comportamentais que, muitas vezes, trazem prejuízos irreversíveis" (p. 25).

Ainda de acordo Silva (2010) para que possa haver predisposição genética, o ambiente externo desencadeia os problemas decorrentes do bullying. A autora (SILVA, 2010 p. 25 a 32) especifica algumas consequências:

- Sintomas psicossomáticos: São sintomas físicos, como cefaleia, cansaço crônico, insônia, dificuldade de concentração, náuseas, palpitações, alergias, sudorese e vários outros, os quais podem causar um alto nível de desconforto e prejuízos nas atividades cotidianas da pessoa;

- Fobia Escolar: Consiste em intenso medo de frequentar a escola. Não somente o bullying causa este problema, mas é um dos motivos que muitos alunos sofrem cada vez que precisam frequentar o ambiente escolar;

- Transtorno de Estresse Pós-Traumático (TEPT): É um trauma que algumas pessoas passam em decorrência de acidentes, sequestros em que há perigo iminente de morte. Porém, vários adolescentes em situação de bullying que sofreram ou presenciaram violência extrema, acabam por desenvolver este transtorno;

Anorexia e Bulimia: Transtorno alimentar que causa sérios problemas de saúde podendo levar a morte. Tanto a bulimia quanto a anorexia podem ser desencadeadas pelo bullying, já que há os padrões de uma autoimagem corporal influenciada pela sociedade, principalmente, em adolescentes, devido as suas mudanças fisiológicas;

Transtorno do pânico: Também pode ser ocasionado pelo bullying, causa ansiedade, taquicardia, medo infundado, medo de sentir medo, pode ainda ser acompanhado de calafrios, boca seca, dilatação da pupila, sudorese;

- Transtorno de Ansiedade Generalizada (TAG): Sensação de medo e insegurança persistente costuma ter insônia, irritabilidade, precisa ser tratado pra não desencadear outros transtornos até mais graves;

- Transtorno Obsessivo-compulsivo (TOC): Conhecido como "manias", caracteriza-se por pensamentos ruins, causa ansiedade e sofrimento. Para aliviar este sofrimento, quem possui TOC, adquire comportamentos repetitivos, ou seja, compulsões. O bullying por ter momentos de intenso 
estresse, abrindo um quadro de TOC em pessoas com predisposição genética ou acentuar o problema já existente;

Depressão: A depressão é outra consequência do bullying, causando isolamento, inclusive no âmbito familiar, baixo desempenho escolar e irritabilidade.

Quadros menos frequentes, citados pela autora (Silva (2010):

Esquizofrenia: Também conhecida como psicose, faz com que a pessoa rompa com a realidade, vivenciando um mundo imaginário, caracteriza-se por delírios, alucinações;

Suicídios e Homicídios: Ocorrem quando o jovem não consegue lidar com a violência sofrida e toma atitudes extremas.

\subsection{Protagonistas do bullying}

Segundo Silva (2010)é importante identificar os alunos envolvidos em bullying para traçar estratégias de enfrentamento. Cada um dos sujeitos desempenha papel neste cenário. A autora expõe cada um deles de acordo com um comportamento típico:

\section{a) Agressores:}

Podem ser do sexo masculino ou feminino, agem através da força física e assédio psicológico, sozinhos ou em grupo. São impulsivos e necessitam dominar os outros, normalmente são acompanhados por grupos de colegas mais inseguros e a eles exercem sua liderança. Na escola começam com brincadeiras de mau gosto, apelidos pejorativos e ridicularizantes, podem fazer ameaças, perturbar e intimidar.

\section{b) As vítimas:}

Podem ser divididas em três tipos conforme sua atuação. A vítima típica é reservada, pouco sociável, sem condições de reagir às agressividades. A vítima provocadora acaba por insuflar nos colegas reações agressivas que vão contra si mesmas e por fim, a vítima agressora, a qual reproduz as agressões sofridas como forma de compensação, "se bater, leva".

As vítimas expressam alguns sinais de que são alvos de bullying, um deles é o isolamento, pois se recusam a ter uma vida social, apresentam ainda baixo rendimento escolar e diminuição da autoestima. Dificilmente contam o que lhes acontece com medo de retaliação por parte dos agressores.

\section{c) Espectadores:}

Também participa do ato de bullying, já que é uma testemunha do que ocorre. Podem ser ativos, não participam ativamente da violência, mas incentivam com palavras ou risos as agressões, os passivos que nada fazem por medo de serem os próximos e ainda há aqueles que ficam neutros por diversos motivos, ficando inertes aos ataques que presenciam. Silva (2010) acrescenta ainda que a omissão alimenta a impunidade contribuindo para o crescimento da violência por parte de quem a pratica.

Fante (2018) salienta que mesmo os espectadores não sofrendo agressões diretamente, podem se sentir inseguros e incomodados, chegando a reagir negativamente, já que seu direito de aprender 
em um ambiente seguro e solidário foi violado, isso virá a influenciar sua capacidade e progresso acadêmico e social.

\section{LEGISLAÇÃO COMO SUPORTE PARA A PREVENÇÃO DO BULLYING}

A Constituição Federal de 1988 traz em seu art. 205 que a educação é direito de todos e dever do Estado e da família, sendo promovida com a colaboração da sociedade, para o pleno desenvolvimento da pessoa e seu preparo para o exercício da cidadania.

Considerando que a educação está inserida na categoria de direito fundamental, porquanto se trata de elemento indissociável ao exercício da cidadania e da dignidade da pessoa humana - fundamentos do Estado Brasileiro -, o direito ao acesso, à permanência e ao sucesso do processo educacional deve ser assegurado às crianças e aos adolescentes de maneira indiscriminada e universal. (ALBINO; TERÊNCIO, 2012, P. 12/13).

O Estatuto da Criança e do Adolescente - (ECA) em seu art. 17 estabelece que o direito ao respeito consista na inviolabilidade da integridade física, psíquica e moral da criança e do adolescente, preservando a imagem, a identidade, a autonomia, dentre outros. Portanto, criar ações que viabilizem o desenvolvimento saudável da criança e do adolescente é papel de todos. (BRASIL. Lei no 8069,1990)

Fante (2018) relata que desde o ano 2000 foram desenvolvidos alguns estudos em escolas paulistas sobre bullying, porém, sem qualquer patrocínio ou incentivo, os estudos atualmente se desenvolvem também no Distrito Federal. "Durante esse tempo, temos nos empenhado no combate ao bullying com o intuito de conscientizar pais, professores, alunos, psicólogos, psiquiatras, pediatras e demais profissionais envolvidos no processo educacional" (FANTE, 2018, p. 50).

Mesmo havendo estudos no Brasil, somente em 2015 foi criada a Lei 13.185, a qual instituiu o Programa de combate ao bullying, prevendo em seu art. $2^{\circ}$ a intimidação sistemática, quando há violência física ou psicológica em atos de intimidação, humilhação ou discriminação, enumerando em seus incisos os tipos de atos tidos como bullying (BRASIL 2015).

Em 29 de abril de 2016 foi publicada a Lei 13.277 (BRASIL, 2016) que institui o dia 7 de abril como o Dia Nacional de Combate ao Bullying e à Violência na Escola. Em 14 de maio de 2018, foi aprovada a lei no 13.663 (BRASIL, 2018) que altera o art. 12 da Lei no 9.394, de 20 de dezembro de 1996 e inclui a promoção de medidas de conscientização, prevenção e combate a todos os tipos de violência e a promoção da cultura de paz entre o compromisso dos estabelecimentos de ensino. O inciso IX trata de todos os tipos de violência, porém, cita especialmente o combate à intimidação sistemática (bullying) o inciso X estabelece ações para promover a cultura de paz nas escolas.

Contatando o aumento desta forma violência a Secretaria Estadual de Educação do Rio Grande do Sul apresentou ao Ministério da Educação projetos com o objetivo de desenvolver ações de combate à violência e ao bullying dentro do ambiente escolar, traçando estratégias conjuntas nas áreas de educação, segurança pública e justiça. Tais projetos consistem em utilizar games e ferramentas de diálogo entre escola e comunidade (GAVA, 2018).

Em 2012 foi promulgada a Lei Estadual n. ${ }^{\circ} 14.030$ (RIO GRANDE DO SUL, Lei n. ${ }^{\circ}$ 14.030, 2012) dispõe sobre as Comissões Internas de Prevenção de Acidentes e Violência Escolar - CIPAVE - no âmbito da rede de ensino público estadual do Rio Grande do Sul. As Comissões têm várias 
incumbências, dentre elas a de identificar as situações de violência, verificar a circunstância em que ocorrem estimular a fiscalização por parte da própria comunidade escolar, fazendo com que zele pelo ambiente escolar.

\section{FORMAS DE REDUÇÃO DO BULLYING NAS ESCOLAS}

Fante (2018) menciona estudos pioneiros no Brasil desde o ano 2000, os quais iniciaram no interior paulista e no Distrito Federal. O estudo envolve palestras, seminários, congressos, o incentivo de novos estudos e pesquisas sobre o tema, além de promoverem cursos de capacitação com o objetivo de identificar e intervir no bullying. Diz que é alarmante a pouca conscientização deste fenômeno nos meios educacionais, assim como a falta de preparo para lidarem com a violência, mas ressalta que o interesse pelo tema tem crescido.

Debarbieux (2011) afirma que o bullying nas escolas deveria ser assunto a ser tratado com profundidade, destacando a formação docente com o intuito de aproximar professores e alunos, havendo ainda a necessidade da escola e da família colaborar entre si. Ressaltando-se ainda que seja importante investir em capacitação dos profissionais que atuam na escola.

A maioria dos estudos de larga escala realizados pelos principais organismos internacionais, procurou explorar os contextos violentos e os diferentes tipos de violência que emergiam no ambiente escolar a partir da percepção de crianças e adolescentes. A preocupação central desses estudos busca saber como a violência é percebida, entendida e representada pelos alunos dentro do ambiente escolar, como vítimas, espectadores e agressores. (SILVA, 2006, p.40).

Fante (2018) afirma a importância de se conhecer a realidade da escola, salientando o compromisso e envolvimento da instituição, familiares e comunidade para alcançar os resultados positivos. $\mathrm{Na}$ mesma perspectiva Pereira (2009) afirma que não há uma receita pronta para o combate ao bullying, pois cada escola possui uma realidade diferente e é preciso investigar qual a frequência, quem são os envolvidos e os locais onde ocorre a violência, assim é possível organizar formas de intervenção.

O Programa Educar para a Paz (FANTE, 2018, p.91) consiste na conscientização dos alunos em relação ao bullying, o desenvolvimento da empatia e o comprometimento destes com o bem comum, sendo agentes de transformação e contribuição para a construção de paz na escola. Utiliza estratégias como a obtenção de indicadores para determinar a porcentagem de envolvidos e de onde as agressões acontecem, observações em sala de aula, melhora na supervisão dos alunos nos espaços comuns, além de um roteiro de entrevistas com vítima e agressor, sendo o diálogo o melhor caminho para o êxito.

Fante (2018) enumera as etapas do desenvolvimento do Programa Educar para a Paz, tendo na "Etapa A" a busca do conhecimento da realidade que conta como primeiro passo para a conscientização e o compromisso, ou seja, que as escolas tomem providências para a prevenção da violência, trabalhando ainda as emoções dos alunos para que pensem antes de agir, para que possam lidar com seus medos, angústias e canalizem sua agressividade para ações proativas.

Em relação aos profissionais das escolas sugere-se uma reflexão acerca do desempenho profissional e das atividades com os alunos, importantes para redirecionar as ações pedagógicas no combate às diversas formas de violência que ocorrem na escola. O segundo passo, trata da investigação da realidade escolar, a partir de observação e aplicação de questionários, com o intuito de averiguar os 
casos de bullying. Após esta fase busca-se elaborar material explicativo sobre o bullying escolar e a confecção de uma cartilha pedagógica que pode auxiliar os pais a identificarem se seus filhos estão envolvidos neste tipo de violência, assim como poderia ajudar no próprio trabalho dos profissionais da educação.

A "Etapa B" consiste na busca da modificação da realidade escolar, tendo como primeiro passo a adoção de estratégias de intervenção. Nesta etapa, a comunidade conhece melhor sua realidade, proporcionando condições para modificá-la, pois os problemas que ocorrem na escola passam a ser de todos, abrindo portas para a reflexão e o comprometimento para buscar soluções. Percebe-se que aplicar punição aos agressores e defender as vítimas não é o suficiente para a resolução do problema, é preciso entender os motivos que levam uma pessoa a agredir a outra, assim como as causas que levam as vítimas a permitirem e suportarem as agressões.

Estas etapas são baseadas na conscientização e compromisso de intervir nos problemas, fazendo uma reflexão sobre a violência, tendo com isso consciência da decisão a ser tomada, além de propiciar à comunidade escolar a reflexão sobre sua realidade para que possam exercer a cidadania.

\section{BULLYING NA "ESCOLA M"}

A Escola Municipal de Ensino Fundamental (Escola "M") está situada no município de Jaguarão no Estado do Rio Grande do Sul, fazendo fronteira com o Uruguai através da cidade de Rio Branco. A "Escola M" possui o Ensino Fundamental Completo, contabilizando um total de 330 alunos no ano de 2020 e funciona nos turnos da manhã e tarde, não tendo atividades em turno inverso. Conta com saneamento básico da rede pública, abastecimento de água e energia, local destinado ao esgoto e coleta periódica de lixo. Está localizada em bairro periférico do município, tendo em seu entorno uma Unidade Básica de Saúde (UBS) mercado, capela e pequenas lojas. A direção da escola descreve este bairro "como tranquilo"

Possui ainda biblioteca, laboratório de informática, computadores com internet/banda larga, impressoras, televisão, quadra de esportes, secretaria, sala da direção, sala dos professores, sala para Atendimento Educacional Especializado (AEE) banheiros, refeitório, cozinha, pátio. É acessível às Pessoas com Deficiência tanto nas dependências da escola quanto nos sanitários.

De acordo com anotações no Diário de Campo, resultado de uma reunião agendada com professores, direção e supervisão da escola em 12 de setembro de 2019. Relatos de professores referem "certa falta de comprometimento das famílias". Referem ainda a casos mais graves de bullying que aconteceriam com uma turma tida como "problemática". Foi mencionado ainda o "desrespeito por parte dos alunos em relação aos professores".

Segundo a gestão escolar, as situações de bullying eram registradas em atas e ocorrem com mais frequência e com maior gravidade em uma turma de sexto ano. As providências tomadas pela direção seriam, conversas com os alunos envolvidos e os seus responsáveis, ou seja, as famílias sempre são informadas sobre os acontecimentos. A Diretora da escola falou que algumas ações reduziriam a violência, como palestras, conversas com os alunos e responsáveis. 
A direção aponta que alguns alunos já são adolescentes e outros estão na fase de transição entre a infância e a adolescência ${ }^{5}$. Essa diferença pode gerar um conflito, transformando-se em bullying, já que os comportamentos se diferenciam. O aluno "novo", não repetente é tido como "infantil" em relação aos de mais idade, propiciando os ataques verbais ou até mesmo físicos, além de intimidações.

De acordo com a diretora da "Escola M", "a participação das famílias poderia ser maior", mesmo relatando que "a participação no geral, é boa". Em relação ao bullying, alguns pais ou responsáveis se envolvem e colaboram nos encaminhamos, em busca de soluções. Porém, outros "não se importam quando informados sobre tais ocorrências".

As ações da Direção da "Escola M" ajudam na busca por medidas para evitar o bullying, porém, uma forma eficaz de resolver a violência não se verifica, parecendo que os métodos propostos se constituem medidas paliativas na resolução do problema. Talvez seja necessário elaborar propostas de ações, juntamente com a gestão e professores para minimizar a violência que afeta cotidianamente os alunos.

\section{ESTRATÉGIAS UTILIZADAS PELA "ESCOLA E" PARA A REDUÇÃO DO BULLYING}

Assim como a "Escola M", a Escola Estadual de Ensino Fundamental ("Escola E") também se localiza no município de Jaguarão. Esta escola está localizada no centro da cidade e "o entorno é tranquilo em relação à violência e situação de risco" (fala da direção). No entanto a direção da escola solicita constantemente o policiamento para acompanhar a saída ou entrada da escola, devido ao fluxo em relação ao trânsito por estar localizada na avenida principal.

Em 2020 a escola contou com 314 alunos, nos turnos da manhã e tarde, com atividades de turno inverso, sendo sala de Atendimento Educacional Especializado (AEE) ${ }^{6}$ e Banda Quincas ${ }^{7}$. No decorrer do ano letivo são executadas atividades que propiciam a participação dos alunos, dentre elas, ensaios e apresentações da banda, projetos de meio ambiente, projeto do Serviço de Orientação Educacional (SOE) de monitores de recreio. Ainda é possível realizar outras ações durante o ano como show de talentos, passeios culturais e Sarau Literário.

A partir de uma entrevista com a Orientadora Educacional foi possível fazer um diagnóstico da incidência de bullying na escola, um fenômeno constante que afeta diversos alunos. A violência é constata entre os alunos de idades e níveis diferentes, sendo os casos mais graves entre adolescentes.

5 De acordo com o Estatuto da Criança e do Adolescente, considera-se criança, a pessoa até doze anos de idade incompleto, e adolescente aquela entre doze e dezoito anos de idade. Disponível em: http://www.planalto.gov.br/ccivil_03/leis//8069.htm. Acesso em dez. 2020.

6 Atendimento para alunos com deficiência, transtornos globais de desenvolvimento, altas habilidades/superdotação. Identifica, elabora e organiza recursos pedagógicos e de acessibilidade a fim de eliminar barreiras para a plena participação dos alunos. Dados disponíveis em: $<$ http://portal.mec.gov.br/index.php?\%20option=com_docman\&view=download\&alias=428-diretrizespublicacao\&Itemid=30192>. Acesso em dez. 2021.

${ }^{7}$ A Banda Quincas foi formada através de um projeto realizado pela Escola Joaquim Caetano da Silva, cidade de Jaguarão/RS. A Banda possui entorno de 30 componentes, apresentam-se com indumentária Gaúcha, honrando seu Estado e suas Tradições. Dados disponíveis em <https://www.youtube.com/watch?v=ehoIjxLstk>. Acesso em dez. 2021 
Assim que chega ao conhecimento da gestão, algo que nem sempre acontece, são registradas em atas ou documentos específicos da Orientação Educacional.

O Bullying em si, como um ato de perseguição constante, agressão física, verbal ou psicológica, sem motivo evidente e forma repetitiva, não acontece com frequência, ou seja, essa relação desigual de poder que caracteriza agressor e vítima, muitas vezes é confundida com conflitos entre alunos, que são resolvidos de outra forma (Orientadora Educacional).

Conforme esta orientadora, a equipe gestora da escola procura ficar atenta ao comportamento dos alunos a fim de identificar algum constrangimento. Caso se perceba "situações de bullying, procurase ouvir a todos os envolvidos, sem julgamentos e a partir daí as famílias são chamadas". A orientadora afirma que "as famílias dentro de suas possibilidades participam das atividades promovidas pela escola". Em relação ao bullying, a orientadora relata:

Algumas famílias chegam à escola muito alteradas quando acham que seus filhos estão sofrendo bullying. Então é necessário esclarecer todas as situações ocorridas e verificar se de fato é um caso de bullying ou de desentendimento entre alunos, professores ou funcionários. Então se faz as averiguações através de conversas individuais com os envolvidos e suas famílias. Geralmente todos procuram orientar seus filhos quanto ao procedimento respeitoso com o outro. Mas infelizmente há também quem justifique os atos indevidos de seus filhos baseados no que eles próprios já passaram em algum momento (Orientadora Educacional).

A orientadora educacional esclarece que a escola faz parte do CIPAVE - Comissão Interna de Prevenção de Acidentes e Violência Escolar, fazendo trabalho preventivo de violência, sendo incluído o bullying. Através do CIPAVE é feita mediação de conflitos baseada na cultura de paz ${ }^{8}$, tendo como base ainda a justiça restaurativa9.

O diagnóstico da situação relacionada ao bullying foi construído por uma entrevista com a orientadora educacional, repassado a um professor dos anos finais do ensino fundamental, com o apoio de um questionário contendo perguntas sobre bullying, a fim de verificar a perspectiva do professor em relação a este tipo de violência em sala de aula.

A designação deste professor se dá pelo número de alunos ao qual tem acesso e pela faixa etária destes, fase em que o bullying é muito presente na escola. O professor cita os tipos mais comuns de bullying, o psicológico e verbal, presenciado especialmente entre as meninas. Segundo o professor, nem sempre é bem aceito pelos responsáveis quando são comunicados. Mas, ao perceber se tratar de bullying encaminha para que o setor de orientação de estudantes os acompanhe.

Este professor trabalha com quatro turmas do sétimo ao nono ano, tendo em torno de cem alunos nesta escola. Afirma que "bullying ocorre em sala de aula e tenho presenciado situações da violência entre meninas". E a "posição do professor deve ser a de encaminhar para a direção e orientação educacional assim que percebe não ser apenas um conflito passageiro, mas algo mais grave".

\footnotetext{
${ }^{8}$ Construir uma cultura da paz envolve dotar as crianças e os adultos de uma compreensão dos princípios erespeito pela liberdade, justiça, democracia, direitos humanos, tolerância, igualdade e solidariedade. Dados disponíveis em <https://www.scielo.br/scielo.php?script=sci_arttext\&pid=S1413-85572002000100013>. Acesso em dez. 2020

${ }^{9}$ É um conjunto ordenado e sistêmico de princípios, técnicas e ações. Por meio dos quais os conflitos quecausam danos são solucionados de modo estruturado. Com a participação da vítima, ofensor, famílias, comunidade e sociedade (AMB e CNJ)
} 
O professor afirma ter experiência de ter lecionado em escolas onde havia campanha intensa em relação à prevenção do bullying, incluindo a formação dos professores para lidar com a violência. $\mathrm{Na}$ sua escola atual percebe que, mesmo havendo por parte dos órgãos públicos ações de abordagem em relação ao bullying, através de campanhas de conscientização, há dificuldade em identificar este tipo de violência na escola, por isso um trabalho em conjunto se faz necessário.

O professor salienta que há um trabalho conjunto com orientação educacional e professores para que se identifique situações de bullying para que se possa intervir. Em muitos casos se percebe tratar desta violência, somente quando os efeitos se tornam quase incontornáveis, levando a muito mais violência. Em sala de aula os professores são base para detectar sinais de bullying que afetam os sujeitos da educação, podendo tomar as providências para tratá-los.

Questionado sobre os motivos que levam uma criança ou adolescente a praticar o bullying, expõe que:

É difícil afirmar sobre tal comportamento, porém, pode haver um contexto familiar em que o jovem sofra ou presencie algum tipo de agressão, é imprescindível que seja transmitido por parte da família o respeito ao próximo, pois o aluno vai reproduzir na escola o que vivencia. (Professor anos finais).

Este professor afirma ainda que a procura pela aceitação no grupo ao qual está inserido, torna o aluno um espectador do bullying para fazer jus ao seu lugar no time. A partir do depoimento do professor, se faz necessário trabalhar com este aluno para não utilizar a omissão em relação à violência para ser aceito no grupo.

Para o desenvolvimento da pesquisa foi feita uma entrevista semiestruturada com três mães que têm filhos nos anos iniciais e finais do ensino fundamental. Estas mães são aqui identificadas por codinomes, sendo utilizada a letra " $M$ ", referente à "mãe", seguida da numeração em ordem crescente de acordo com a exposição no texto, seguida de suas profissões. A entrevista contempla informações pessoais, visão das mães sobre o bullying e o papel da gestão para enfrentá-lo.

"M1", mãe e bibliotecária, define o bullying como uma violência física ou psicológica de uma pessoa contra outra que causa mágoa. As agressões podem ser verbais e físicas que causam medo, tristeza e baixa autoestima. Quando questionada sobre os motivos que levam uma criança ou adolescente a praticar o bullying, diz que "possivelmente o praticante quer se sentir dominante, como forma de 'aparecer' para os amigos como superior, já que faz outra pessoa ser submissa à suas agressões".

Na opinião desta mãe, "para perceber se o filho ou filha é alvo de bullying, além de observar, é preciso manter uma relação de confiança, assim haverá diálogo". Relata que uma das filhas "foi alvo de bullying por ser muito tímida, foi isolada do resto do grupo". É algo típico entre as meninas, chamado bullying indireto, o qual além de isolar, pode espalhar boatos maldosos, afetando a vítima psicologicamente. A entrevistada acha ainda que a escola poderia fazer mais, redobrando a atenção para que casos assim não ocorressem.

"M2", mãe e nutricionista, define o bullying como uma discriminação de diferentes tipos, classe social, raça, aparência física, sexo, dentre outros. "Os agressores atuam com atos maldosos e desagradáveis, através de ataques verbais e físicos, trazendo problemas psicológicos para as vítimas, as quais carregam traumas para toda a vida, se não for tratado, podem levar ao suicídio". 
Esta mãe cita como consequências de quem sofre o bullying, "a baixa autoestima, sentimentos de culpa, ódio, solidão, assim como problemas de aprendizagem" que podem levar as vítimas a "não socializar e entrar em depressão". Acredita que os "motivos de uma criança ou adolescente praticar o bullying está no círculo familiar, por não receber atenção da família ou por sofrer bullying no interior desta". Afirma ainda que "é preciso prestar atenção nas mudanças de comportamento dos filhos, além de conversar muito, só assim poderá perceber as situações de bullying vivenciadas por estes".

Quanto aos casos de bullying na escola, "M2" afirmou que "soube através das filhas sobre as questões de violência, as quais ocorreram mais de uma vez". Destaca que "a escola atualmente está trabalhando em sala de aula sobre bullying, mas deveria haver ações mais eficazes por parte da instituição". Pontua que "os profissionais da educação deveriam dialogar mais sobre o tema e aumentar os cuidados, principalmente no intervalo, momento em que o bullying se faz mais presente".

"M3", mãe e Farmotécnica, define o bullying como "atitudes ruins que baixam a autoestima, havendo certa falta de respeito às diferenças". Destaca que as vítimas de bullying "acabam tendo baixa autoestima, se retraem e sentem tristeza". Ressalta que a base é a família, mesmo muitas crianças ou adolescentes terem sua própria opinião, é importante sempre frisar que estas "devem respeitar como cada pessoa é mostrando que o preconceito é algo inaceitável".

Esta mãe salienta que "os pais devem ficar atentos ao comportamento dos filhos, observar se continuam com a mesma rotina, se não apresentam tristeza ou isolamento". Não se lembra de ter testemunhado casos de bullying, mas entende a gravidade deste. Por isso, defende a ideia de um trabalho conjunto da escola com as famílias, começando desde cedo, na pré-escola a fim de mudar a mentalidade em relação a esta violência.

"M3" compreende que é um "problema social" e que "os pais precisam estar cientes de que a brincadeira com o coleguinha, nem sempre é saudável e não pode ser vista como algo normal". Apesar de deixar claro que o bullying não deixa de ser debatido em aula, diz que deveria haver um engajamento maior de todos, a escola sozinha não teria condições de alterar por completo a situação, necessitando que todos se envolvessem.

Os entrevistados destacam, em suas respostas uma visão de que bullying se origina no ambiente familiar e é transferido para escola. Há esperança de que haja medidas de prevenção desta forma de violência. Segundo eles a escola deve ser local seguro para que as famílias sintam-se confortáveis em deixar seus filhos. Em contrapartida a família deve ser aliada da instituição no combate ao bullying, na luta contra todo tipo de violência para que crianças e adolescentes desenvolvam-se plenamente.

\section{CONSIDERAÇÕES FINAIS}

As duas escolas aqui apresentadas foram selecionadas por serem públicas e possuírem o ensino fundamental completo. A recepção em ambas às escolas foi acolhedora, sendo que a estratégia de contato inicial foi com as diretoras, passando a seguir à supervisora e orientadora educacional.

O objetivo com os encontros iniciais foi detectar a incidência de bullying, assim como as ações realizadas pela gestão. A proposta de incluir duas escolas na pesquisa foi aprofundar a escola sem estratégia definida para enfrentamento do bullying e a outra que busca realizar práticas baseadas na cultura de paz para a resolução de conflitos existentes, principalmente, quando se trata de bullying. 
Para atender ao objetivo de verificar as incidências desta violência e o papel da gestão para enfrentála, na "Escola M", a entrevista foi feita com a diretora que ressaltou medidas paliativas e pontuais, não muito eficazes para a resolução do conflito. As ações pontuais envolvem conversa com os envolvidos e seus responsáveis, em que são resolvidas as situações de violência no momento em que aparecem e apenas naquele caso.

Há, portanto a necessidade de estratégias de enfrentamento do bullying de uma forma mais ampla, trabalhar com alunos através de atividades que visem à conscientização, salientando a importância do respeito ao próximo, assim como às diferenças e fazer um trabalho conjunto com as famílias informando-as de que bullying é algo sério e que precisa ser combatido.

$\mathrm{Na}$ "Escola E" a entrevista foi feita com três mães, cujo critério principal era ter filhos ou filhas em anos iniciais e finais do ensino fundamental e com um professor que tivesse acesso às turmas de anos finais por ser a fase com maior índice de bullying. As medidas tomadas pela escola até então têm sido eficazes, já que os alunos estão procurando mais por ajuda, sendo possível com isso mediar situações de violência.

Identificar os casos de bullying em sua fase inicial permite o tratamento adequado e pode evitar consequências mais sérias. Conhecer esta situação requer acompanhar os sujeitos e estabelecer relações de confiança, em sintonia com a gestão desta instituição. Por mais que estratégias voltadas à cultura de paz estejam sendo efetuadas, ainda não atingiram um número significativo para a resolução de conflitos relacionados ao bullying.

A pesquisa aponta que Bullying nas escolas é algo ainda corriqueiro, uma forma de violência percebida que exige a atenção dos gestores das escolas, sendo ainda difícil para a gestão executar ações que combatam a violência. O envolvimento da família com a gestão da escola pode contribuir para diminuir possíveis impactos causados por frequentes agressões. Contudo, a prevenção ainda é a melhor forma de combater o bullying.

Nas escolas pesquisadas, a violência conhecida como bullying, é uma preocupação constante, na "Escola E", mesmo com os trabalhos voltados para a cultura de paz, a escuta ainda não consegue evitar a violência. Torna-se necessário recolher mais informações e desenvolver um trabalho de formação e conscientização com alunos como primeiro passo para vencer esta forma de violência, aliada ao esclarecimento da família e da comunidade.

Espera-se que as escolas sejam ambientes seguros e saudáveis para que as crianças e adolescentes desenvolvam seu potencial tanto intelectual como social. Não pode ser um local em que sofram violências, que podem levar a danos físicos ou psicológicos. Os atos de violência não podem ser naturalizados ou entendidos como brincadeiras inocentes da fase pueril. Trabalhar o respeito, a tolerância e a resiliência farão com que se moldem os sujeitos em formação, a fim de que se desenvolvam plenamente e de forma saudável, respeitando as diferenças e exercendo a empatia.

\section{REFERÊNCIAS}

ALBINO, Priscilla Linhares; Marlos Gonçalves TERÊNCIO. Considerações críticas sobre o fenômeno do bullying: Do conceito ao combate e À prevenção. Revista eletrônica do CEAF, Porto Alegre. Vol. 1, n.2, fev/maio2012. Acesso em: 05 dez.2020. 
AMB (Associação dos Magistrados Brasileiros) e CNJ (Conselho Nacional de Justiça). Justiça Restaurativa do Brasil - A paz pede a palavra, Porto Alegre, 2015. Disponível em: https://www.amb.com.br/jr/docs/cartilha_.pdf. Acesso em dez. 2020.

ANDRADE, Mariana. Virginia Tech Killer: o maior massacre a uma universidade dos Estados Unidos. Canal Ciências Criminais. Publicado em 7 dez, 2017. Disponível em: https://canalcienciascriminais.com.br/virginia-tech-killer/. Acesso em 30 dez. 2020

ASSOCIAÇÃO BRASILEIRA DE NORMAS TÉCNICAS. NBR 6023: Informação e documentação: Referências. Rio de janeiro, p. 24. 2002.

BASTOS, Maria Clotilde Pires; FERREIRA, Daniela Vitor. Metodologia Científica - Londrina: Editora e Distribuidora Educacional S.A, 2016.

BRASIL, Lei No 13.185 de 06 de novembro de 2015. Institui o Programa de Combate à intimidação Sistemática (Bullying). Brasília, DF, 2015. Disponível em: http://www.planalto.gov.br/ccivil_03/_ato2015-2018/2015/lei/l13185.htm. Acesso em: 05 dez.2020.

BRASIL, Lei No 13.277 de 29 de abril de 2016. Institui o dia 7 de abril como o Dia Nacional de Combate ao Bullying e à Violência na Escola. Brasília, DF, 2016. Disponível em: https://legis.senado.leg.br/norma/602502. Acesso em: 05 dez.2020.

BRASIL. [Constituição (1988)]. Constituição da República Federativa do Brasil. Disponível em: http://www.planalto.gov.br/ccivil_03/constituicao/constituicao.htm. Acesso em: 05 dez.2020.

BRASIL. Lei No 13.663 de 14 de maio de 2018. altera o art. 12 da Lei no 9.394, de 20 de dezembro de 1996. Para incluir a promoção de medidas de conscientização, de prevenção e de combate a todos os tipos de violência e a promoção da cultura de paz entre as incumbências dos estabelecimentos de ensino. Disponível em: http://www.planalto.gov.br/ccivil_03/_ato2015-2018/2018/lei/L13663.htm. Acesso em: 05 dez.2020.

BRASIL. Lei no 8069 de 13 de julho de 1990. Estatuto da Criança e do Adolescente. Dispõe sobre o Estatuto da Criança e do Adolescente e dá outras providências. Disponível em: https://www.planalto.gov.br/ccivil_03/leis/l8069.htm. Acesso em: 05 dez.2020.

CARREIRAS, Débora Bianca Xavier. Violência nas escolas: Qual é o papel da gestão? Disponível em: https://bdtd.ucb.br:8443/jspui/bitstream/123456789/828/1/Debora\%20Bianca.pdf. Acesso em: 04 dez.2020.

CASTRO, Lana Weruska Silva. O atirador de Realengo. Canal Ciencia Criminais. Disponível em: https://canalcienciascriminais.jusbrasil.com.br/artigos/579821221/o-atirador-de-realengo . Acesso em 30 dez. 2020.

DEBARBIEUX, Eric. Entrevista concedida à Lúcia Müzel. Nova escola. 01 de Dezembro de 2011. Disponível em: https://novaescola.org.br/conteudo/893/eric-debarbieux-fala-sobre-ocombate-ao-bullying. Acesso em 05 dez.2020.

FANTE, Cleo. Fenômeno Bullying: Como prevenir a violência nas escolas e educar para a paz -

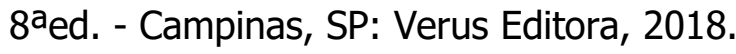

GAVA, Renato. Rio Grande do Sul apresenta ao MEC projetos para combater bullying. Publicação em 08/08/2018 às 18h00min. RS Novas Façanhas. Disponível em: https://estado.rs.gov.br/secretariodo-rs-apresenta-ao-mec-projetos-contra-bullying. Acesso em dez. 2020. 
HOLLAENDER, Arnon; VARELLA,Vidal. The Landmark Dictionary: Para estudantes brasileiros de inglês. 5.ed. São Paulo: Moderna, 2014.

HOUAISS, Antônio. Pequeno Dicionário da Língua Portuguesa. 1.ed. São Paulo: Moderna, 2015. LOURENÇO, Luana. Estudantes mortos em ataque a tiros em Goiânia serão enterrados neste sábado. Jusbrasil. Disponível em: http://agenciabrasil.jusbrasil.com.br/noticias/511639867/estudantes-mortos-em-ataque-a-tiros-em-goiania-seraoenterrados-neste-sabado. Acesso em: 30 dez. 2020.

MARRAN, Phellipe Böy. Columbine: o massacre que apresentou o Bullying ao mundo. Canal Ciências Criminais. Atualizado em 19 out, 2018. Disponível em: https://canalcienciascriminais.com.br/columbine-massacre-bullying/. Acesso em 30 dez. 2020.

MINISTÉRIO DA EDUCAÇÃO. Especialistas indicam formas de combate a atos de intimidação. http://portal.mec.gov.br/component/tags/tag/34487\#: :t\%20ext=Outro\%20\%C3\%ADndice\%20qu e\%20chama\%20bastante,e\%202.118\%20no\%20\%C3\%BAltimo\%20semestre. Disponível em: 10 dez.2020.

NETO, Aramis Lopes. Bullying: Comportamento agressivo entre estudantes. Disponível em: https://www.scielo.br/pdf/jped/v81n5s0/v81n5Sa06.pdf. Acesso em: 11dez.2020.

ORIQUE, Silvia Diana de Lima Silva; HAMMES, Lúcio Jorge. Incidência de Bullying nas escolas públicas e o papel da gestão no enfrentamento da violência. In: SEMEDUC - I Simpósio Nacional de Estratégias e Multidebates da Educação - Saberes que educam. 2020. P. 741-745. Disponível em; http://anais.uesb.br/index.php/semeduc. Acesso em dez. 2020.

PEREIRA, Sônia Maria de Souza. Bullying e suas implicações no ambiente escolar - São Paulo: Paulus, 2009.

RIO GRANDE DO SUL, Lei n.o 14.030, de 26 de Junho de 2012. Disponível em: http://www.al.rs.gov.br/filerepository/repLegis/arquivos/14.030.pdf. Acesso em 06 dez. 2020.

SECRETARIA DE EDUCAÇÃO DO RIO GRANDE DO SUL. Comissões Internas de Prevenção de Acidentes e Violência Escolar (CIPAVE. Disponível em: https://educacao.rs.gov.br. Acesso em: 10 dez.2020.

SILVA, Ana Beatriz Barbosa. Bullying: Mentes perigosas nas escolas - Rio de Janeiro: Objetiva, 2010.

SILVA, Dezir Garcia. Violência e Estigma: Bullying na Escola.São Leopoldo, 2006. Disponível em: http://www.repositorio.jesuita.org.br/handle/UNISINOS/2123. Acesso em: 05 dez.2020.

SUDRÉ, Lu. Como estão as vítimas do massacre de Suzano, um ano após o ataque? Estudantes da E.E. Raul Brasil falam ao Brasil de Fato sobre consequências psicológicas do episódio que causou 10 mortes. Brasil de Fato | São Paulo (SP) | 13 de Março de 2020. Disponível em: https://www.brasildefato.com.br/2020/03/13/como-estao-as-vitimas-do-massacre-de-suzano-umano-apos-o-ataque. Acesso em $30 \mathrm{dez} .2020$.

Submissão: 08/08/2021

Aceito: 18/08/2021 